\title{
Lifestyle Related Fertility Disorders in North Jordan: Potential for Improvement
}

\author{
Jehan Mahmoud Hamadneh ${ }^{*}$, Zouhair Amarin', Shereen Hamadneh², Nail A. Obeidat ${ }^{1}$, Manal Kassab ${ }^{3}$, \\ Mahmoud Bani Hani ${ }^{4}$
}

\begin{abstract}
Objectives: To explore the prevalence rates of lifestyle practices linked to fertility disorders.

Materials and Methods: A cross-sectional descriptive study, using a validated questionnaire, was conducted among sub-fertile couples attending the fertility center at Jordan University of Science and Technology between February 2013 and August 2014. Results: A total of 126 couples took part in the study. The average length of sub-fertility was 4.2 years. The mean age of the women was 31 years, of whom $70 \%$ were $<35$ years of age. Over $6 \%$ engaged in regular sporting activity. Less than $1 \%$ of women smoked more than 5 cigarettes per day. For male partners, the mean age was 36 years, of whom $85.7 \%$ were $<45$ years of age. Over $22 \%$ engaged in regular sporting activity. None were taking anabolic steroids on a regular basis. Almost $39 \%$ of men smoked more than 5 cigarettes per day. The percentage of patients that took advantage of the woman's "fertile days" on 6 occasions over the preceding 6 months was $29.37 \%$. Low stress was encountered in $24.21 \%$, intermediate stress in $40.08 \%$, and high stress in $34.52 \%$ of couples. The most frequent cause of stress was delay in achieving pregnancy. Almost $4 \%$ of women displayed 2 or more risk factors, compared to $11.1 \%$ in their male counterparts.

Conclusion: Behavior-related fertility disorders are common in Jordan. Modifying lifestyle factors for better reproductive health is highly recommended.

Keywords: Behavior, Fertility, Lifestyle
\end{abstract}

\section{Introduction}

Current evidence indicates a $9 \%$ prevalence of infertility (1). Patients that are hoping to get pregnant might wonder about their fertility and whether they can improve it. There is an increasing body of evidence that lifestyle factors can influence reproductive health. The post-industrial era is associated with an excessive exposure to certain lifestyle factors and behaviors that have the potential for a positive or negative effect on reproductive performance (2).

Some factors might be beyond patients' control, such as medical issues that affect both male and female fertility, but other lifestyle factors, such as nutrition, weight, exercise, psychological stress, and age of starting a family can be modifiable (2).

Negative effects of lifestyle factors such as environmental and occupation exposure, illicit drug use, cigarette smoking, medications, weight management, exercise, alcohol and caffeine consumption are well documented (3-6). Lifestyle-related fertility disorders were estimated to be responsible for $5 \%$ of all cases of subfertility (7). To enhance fertility, such lifestyle factors, once identified, can be modified.

The findings of the effect of body weight on fertility are firmly established in both sexes. Pathophysiologically, being over or underweight would lead to hormonal changes that would lead to oligomenorrhea and anovulation with subsequent subfertility (8-14).

Studies investigating sporting behavior indicate that excessive sport, in terms of frequency, duration and intensity have a negative effect on hormone balance and reproductive performance. The findings of these studies were independent of the confounding factors of age, smoking or body mass index (BMI) (15-19).

There is a plethora of studies that document the detrimental effect of smoking on both male $(20,21)$ and female reproductive performance $(22,23)$. Research indicates that smoking impairs sperm count, motility, morphology and fertilization capacity (20). Women smokers have a significantly smaller number of pregnancies and a higher incidence of miscarriages and ectopic pregnancies (23).

Commonly encountered drugs and medications may be detrimental to semen parameters and male sexual performance (24). These agents may exert a gonadotoxic effect on the testicles, alter the hypothalamic-pituitary-gonadal axis, and impair ejaculation, erectile function and libido (25).

Recreational drugs can affect male fertility. The long-

Received 7 January 2017, Accepted 14 June 2017, Available online 8 July 2017

${ }^{1}$ Department of Obstetrics and Gynaecology, Faculty of Medicine, Jordan University of Science and Technology (JUST), Irbid, Jordan. ${ }^{2}$ Department of Maternal Child Health, Faculty of Nursing, Al-Albayt University, Mafraq, Jordan. ${ }^{3}$ Department of Maternal and Child Health, Faculty of Nursing, Jordan University of Science and Technology, Irbid, Jordan. ${ }^{4}$ Oncoplastic Breast Specialist, Medical Director, Princess Basma Teaching Hospital, Irbid, Jordan.

*Corresponding Author: Jehan Mahmoud Hamadneh, Tel: +962-799166694, Email: jehan_hamadneh@yahoo.com 
term effects of alcoholism include erectile dysfunction, reduced libido and gynecomastia (26). Many studies have suggested that the mutagenic and carcinogenic components of recreational drugs significantly impair sperm count, motility and morphology (27).

Illicit drugs affect the reproductive performance of men. Marijuana interferes with spermatogenesis (26). Opiates adversely affect libido and erectile function and suppress the hypothalamus and pituitary gland. Cocaine impairs erectile function, and amphetamines cause diminished libido (27).

Some prescription drugs impair reproductive performance. The use of antihypertensives, thiazide diuretics and beta-blockers may compound inadequate blood flow to the male genitals and affect potency and libido. Spironolactone inhibits the production of testosterone, prevents the binding of dihydrotestosterone, results in erectile dysfunction and impairs spermatogenesis $(25,26)$.

Calcium channel blockers may inhibit the normal fertilization process by affecting acrosome reaction (28). Alpha-adrenergic blockers, commonly prescribed for benign prostatic hyperplasia and voiding complaints, may cause retrograde ejaculation (29).

Psychotherapeutic agents can lead to erectile dysfunction and reduced libido. Most antipsychotics block dopamine in the CNS and may have alpha-adrenergic blocking effects on the innervation of the internal genital organs, in addition to possible erectile dysfunction (26).

Tricyclic antidepressants, selective serotonin reuptake inhibitors, and phenothiazines have the potential to lead to erectile dysfunction, reduced libido, and impaired ejaculation. In addition, antidepressants may cause substantial elevation in serum prolactin concentrations, with suppression of gonadotropin releasing hormone and inhibition of luteinizing hormone binding to Leydig cells in the testes, with subsequent impaired spermatogenesis. Other psychotherapeutic agents such as monoamine oxidase inhibitors and lithium carbonate can cause erectile dysfunction and ejaculatory problems (26).

Hormonal agents may influence male fertility. Anabolic steroids are being used by body builders and athletes. These agents cause hypogonadotropic hypogonadism and erectile dysfunction by decreasing production of endogenous testosterone. High doses have been associated with oligoasthenoteratozoospermia (25-29). Several commonly prescribed individual agents within each of the major classes of antibiotics may significantly affect fertility. Significant alterations in semen parameters have been documented in patients taking nitrofurans and sulfasalazine. Other commonly used antibiotics, such as erythromycin, may reduce sperm motility and density. Tetracyclines bind to mature spermatozoa and have the potential to affect sperm motility. Gentamicin and neomycin may directly inhibit spermatogenesis (30).

Mental and emotional psychological stress may reduce female reproductive performance by affecting the autonomic nervous, endocrine and immune systems (31). However, the impact of mental and emotional stress on fertility is ambivalent $(7,32,33)$. Given that infertility is associated with stress (34-36), it is not clear whether stress contributes to or is a consequence of subfertility.

The prevalence of sexual dysfunction in subfertile couples remains unclear (37). Sexual disorders as a cause of subfertility are relatively unusual (38). The relationship between sexual disorders and infertility can be reciprocal. Sexual dysfunction may cause difficulty conceiving, and vice-versa, being unable to conceive may cause sexual dysfunctions. Sexual dysfunctions resulting from diagnosis and medical therapy are common in couples with fertility problems, with women being more frequently affected than men (39).

The aim of this study was to review the impact of a specific range of contemporary lifestyle factors that may negatively affect the reproductive performance of subfertile couples. This review focuses on non-communicable modifiable lifestyle factors that may affect fertility. These factors include male and female age, weight, diet, exercise, smoking, caffeine consumption, alcohol consumption and psychological stress.

\section{Materials and Methods}

A cross-sectional design utilizing a validated questionnaire was conducted between February 2013 and August 2014. The questionnaire was based on reviewed literature, with special reference to research on behaviors that affect human fecundity. The focus aimed at elements that may affect natural fertility. Lifestyle factors that affect assisted reproductive technologies were excluded.

The questionnaire included questions with pre-formulated answer options. The questions on sporting activities were based on the compendium of physical activity (40), and time frame of the sporting activity per week (41).

Data were analyzed using SPSS 19 (SPSS, Inc., Chicago IL, USA).

\section{Results}

A total of 126 couples took part in the study. The average length of subfertility was 4.2 years. Women and men with a BMI $>25$ composed $38.0 \%$ of subjects. The mean age of women was 31 years, of whom $70.6 \%$ were $<35$ years of age, $4.7 \%$ had a $\mathrm{BMI}<18.5,41.2 \%$, and $0.79 \%$ felt that they ate more or substantially more, $6.3 \%$ engaged in regular sporting activity, with an average $2.9 \mathrm{~h} / \mathrm{wk}$, of whom $11.9 \%$ practiced sport for more than $4 \mathrm{~h} /$ wk. Less than $1 \%$ of women smoked more than five cigarettes per day, or regularly took medicines that were detrimental to fertility. None drank alcohol more than twice per week. In women the most frequent cause of distress was delay in getting pregnant.

The mean age of male partners was 36 years, of whom over $85.7 \%$ were $<45$ years of age, over $11.1 \%$ indicated that they ate less or much less than other men, 3.1\% felt that they ate more or substantially more, $22.2 \%$ engaged in regular sporting activity, with an average of $2.9 \mathrm{~h} / \mathrm{wk}$, of whom $12.7 \%$ practiced sport for more than $4 \mathrm{~h} / \mathrm{wk}, 38.9 \%$ of men smoked more than 5 cigarettes per day. None 
drank alcohol more than twice per week. None were taking anabolic steroids or medicines, on a regular basis, that were detrimental to fertility. The most frequent cause of stress was delay in achieving pregnancy.

The percentage of patients that failed to take advantage of the woman's fertile days on no occasion over the preceding 6 months was $2.7 \%$, in contrast to $29.3 \%$ that took advantage of this window in 6 out of 6 occasions. The reasons for this were "no inclination," "psychological grounds" and "sexual disorders" in $35.7 \%$ of respondents.

The percentage of couples that had delayed one diagnostic investigation or more for childlessness for 3 months or more, despite the advice given to them by their doctors, and despite having adequate time was $19.0 \%$.

Patients fulfilling at least one of the following criteria: women with a BMI $<18.5$, women that exercised excessively, men or women that smoked $>5$ cigarettes/day, men that used anabolic steroids, and men or women with dyspareunia and sexual abstention for 6 months were singled out and analyzed for possible behavior-related risk factors. This applied to $36.5 \%$ of the 126 female respondents, and to $53.9 \%$ of the 126 male respondents. The percentage that displayed two or more risk factors was $3.9 \%$ of the 126 females, and $11.1 \%$ of the 126 males.

On a scale from 0 to 5 of subjective stress assessment, low stress was encountered in $24.2 \%$, intermediate stress in $40.0 \%$, and high stress in $34.5 \%$ of couples attempting conception.

\section{Discussion}

Medical literature has identified many lifestyle elements that are amenable to modifications with the view of improving overall fertility. Examples include age of starting a family, nutrition, weight management, exercise, cigarette smoking, recreational and prescription drug use, alcohol and caffeine consumption, psychological stress and others (2-7).

In this study, the mean age of women and men was 31 years and 36 years, respectively. Evidence suggests that age plays an important role in fertility. Previously, reduction in fertility with age was attributed only to the female. In studies that controlled for female age, successful pregnancy was higher in those with a younger male partner. Thus, initiating pregnancy before the age of 30 for women and before 35 for men may provide the highest level of fecundity (42).

Weight may affect fertility. Obesity has a major effect on ovulation but smaller effect on semen quality. In addition, excess body weight increases the risk of miscarriage, stillbirth and preterm birth (43). In the present study, the percentage of women and men, with BMI $>25$ was $38.0 \%$. This high percentage necessitates further investigation of the fertility status of overweight, obese and morbidly obese male and female partners.

Exercise is beneficial. It has positive effects for the male. Moderate physical activity in men is associated with significantly better sperm parameters (44). In contrast, for the female, it may be associated with a reduced fecundity
(45). Underweight men or women who exercise vigorously may be at an increased risk of being subfertile $(46,47)$. In this study, the percentage of women and men that practiced sport more than $4 \mathrm{~h} /$ wk was $11.90 \%$ and $12.70 \%$, respectively. The stress of excessive exercise may add to the already existent stress of subfertility and further confound the problem.

In this study, the percentage of the women and men that smoked more than 5 cigarettes per day was 0.79 and $38.8 \%$, respectively. Smoking adversely affects the quality of gametes. Cigarette smoke contains over 4000 chemicals (48). Female smoking and second-hand smoke was found to be detrimental to oocyte quality and implantation with an increase in miscarriage rate. In addition, smoking tends to reduce ovarian reserve and disrupt the normal hormone levels of FSH and progesterone (49,50). In men, smoking tends to decrease semen volume, sperm count, density, motility, normal morphology and fertilizing capacity. In addition, it increases sperm DNA fragmentation, with an increase in miscarriage rate (51-53). Furthermore, exposure to cigarette smoke is a leading cause of unexpected infant death syndrome (54).

In men, alcohol consumption has been linked to many negative side effects such as testicular atrophy, decreased libido, oligozoospermia and teratozoospermia $(55,56)$. Women who drink alcohol have an increased rate of anovulation, abnormal blastocyst development, luteal phase dysfunction, decreased implantation rate, increased risk of spontaneous abortion and fetal death (57-59). The degree of the detrimental effects of alcohol on reproductive performance is proportional to the amount of alcohol consumed (60). None of the male or female participants in this study drank alcohol more than twice per week. This is explained by the fact that most Middle Eastern countries strictly control the consumption of alcohol or ban it altogether.

In this study, on a scale of 0 to 5 of subjective stress assessment, low stress was encountered in $24.2 \%$, intermediate stress in $40.0 \%$ and high stress in $34.5 \%$ of couples attempting conception. Stress has been implicated in influencing reproductive performance, whether it is physical, social or psychological. Males who experience stressful life events are more likely to be affected by low sperm concentration, decreased motility and higher percentages of abnormal morphology $(61,62)$.

Stress is thought to affect the hypothalamic-pituitary-gonadal access, and ultimately reduce testosterone and luteinizing hormone levels, resulting in a disruption of gonadal function and spermatogenesis (62). Furthermore, actively coping with stress may cause adrenergic activation, leading to vasoconstriction in the testes, resulting in lower testosterone levels and decreased spermatogenesis $(63,64)$. Decreased stress levels have been associated with an improvement in fertility (65).

Various studies have shown reduced success rate in achieving pregnancy in women experiencing anxiety, stress, and depression, with certain individuals being more vulnerable than others (66). Infertility itself is 
stressful, due to the societal pressures, testing, diagnosis, treatments, failures, unfulfilled desires, and financial costs (67). Stress reduction programs have been shown to benefit couples attempting conception (65). Receiving instruction on how to deal with stress may significantly improve the chances of conception.

A higher conception rate is achieved by women who participate in cognitive behavioral interventions and support groups than in women who do not participate in such groups (65). Positive moods correlate with better take home baby rates (68). The implementation of guidelines on behavior-related subfertility would improve communication and counseling of couples attempting conception (69).

The limitation of this study is that the sample consisted of couples undergoing medical investigation at an assisted reproduction center. Not all subfertile couples seek medical treatment, therefore, the generalized ability of the results is restricted.

\section{Conclusion}

A high percentage of couples who attend assisted reproduction centers are likely to be affected by lifestyle-related subfertility. Most lifestyle factors are theoretically modifiable, therefore, a structured programme of counselling would optimize the chances of success and minimize the need for costly and invasive subfertility treatment.

\section{Ethical Issues}

All procedures performed in this study involving human participants were in accordance with the ethical standards of the institutional research committee and with the 1964 Helsinki declaration and its later amendments or comparable ethical standards. Informed consent was obtained from all individual participants included in the study.

\section{Conflict of Interests}

The authors declare no conflicts of interests with respect to the research, authorship, and/or publication of this article.

\section{Financial Support}

This study received no funding

\section{Acknowledgments}

The authors are grateful to the couples who participated in this study.

\section{References}

1. Boivin J, Bunting L, Collins JA, Nygren KG. International estimates of infertility prevalence and treatment-seeking: potential need and demand for infertility medical care. Human Reprod. 2007;22(6):1506-12. doi:10.1093/humrep/ dem046.

2. Sharma R, Biedenharn KR, Fedor JM, Agarwal A. Lifestyle factors and reproductive health: taking control of your fertility. Reprod Biol Endocrinol. 16;11:66. doi:10.1186/1477-7827-11-66.

3. Centers for Disease Control and Prevention (CDC) (2011)
Reproductive Health. Infertility FAQs. http://www.cdc.gov/ reproductivehealth/Infertility/index.htm

4. Homan GF, Davies M, Norman R. The impact of lifestyle factors on reproductive performance in the general population and those undergoing infertility treatment: a review. Hum Reprod Update. 2007;13(3):209-223. doi:10.1093/humupd/dml056.

5. Klonoff-Cohen H. Female and male lifestyle habits and IVF: what is known and unknown. Hum Reprod Update. 2005;11(2):180-203. doi:10.1093/humupd/dmh059.

6. Li Y, Lin H, Li Y, Cao J. Association between socio-psychobehavioral factors and male semen quality: systematic review and meta-analyses. Fertil Steril. 2011;95(1):116-23. doi:10.1016/j.fertnstert.2010.06.031.

7. Wischmann T. Psychogenic infertility-myths and facts. J Assist Reprod Genet. 2003;20(12):485-94. doi:10.1023/ B:JARG.0000013648.74404.9d.

8. Meldrum DR, Casper RF, Diez-Juan A, Simon C, Domar $\mathrm{AD}$, Frydman R. Aging and the environment affect gamete and embryo potential: can we intervene? Fertil Steril. 2016;105(3):548-59. doi:10.1016/j.fertnstert.2016.01.013.

9. Hassan MA, Killick SR. Negative lifestyle is associated with a significant reduction in fecundity. Fertil Steril. 2004;81(2):384-92. doi:10.1016/j.fertnstert.2003.06.027.

10. Fontana R, Della Torre S. The deep correlation between energy metabolism and reproduction: a view on the effects of nutrition for women fertility. Nutrients. 2016;8(2):87. doi:10.3390/nu8020087.

11. Michalakis K, Mintziori G, Kaprara A, Tarlatzis BC, Goulis DG. The complex interaction between obesity, metabolic syndrome and reproductive axis: a narrative review. Metabolism. 2013;62(4):457-78. doi:10.1016/j. metabol.2012.08.012.

12. Nguyen RH, Wilcox AJ, Skjaerven R, Baird DD. Men's body mass index and infertility. Hum Reprod 2007;22(9):248893. doi:10.1093/humrep/dem139.

13. Paasch U, Grunewald S, Kratzsch J, Glander HJ. Obesity and age affect male fertility potential. Fertil Steril. 2010;94(7):2898-901. doi:10.1016/j.fertnstert.2010.06.047.

14. Rich-Edwards WJ, Goldman BM, Willett CW, et al. Adolescent body mass index and infertility caused by ovulatory disorder. Am J Obstet Gynecol. 1994;171(1):1717.

15. Derbyshire E. Taking it a step too far? Physical activity and infertility. Nutr Food Sci. 2007;37(5):313-8.

16. Anderson K, Nisenblat V, Norman R. Lifestyle factors in people seeking infertility treatment - A review. Aust N Z J Obstet Gynaecol. 2010;50(1):8-20. doi:10.1111/j.1479828X.2009.01119.x.

17. Morris SN, Missmer SA, Cramer DW, Powers RD, McShane PM, Hornstein MD. Effects of lifetime exercise on the outcome of in vitro fertilization. Obstet Gynecol. 2006;108(4):938-45. doi:10.1097/01. AOG.0000235704.45652.0b.

18. Gudmundsdottir SL, Flanders WD, Augestad LB. Physical activity and fertility in women: the North-Trondelag Health Study. Hum Reprod. 2009;24(12):3196-204. doi:10.1093/ humrep/dep337.

19. Olive DL. Exercise and fertility: an update. Curr Obst Gynaecol. 2010;22:259-63. doi:10.1097/ GCO.0b013e32833c7227.

20. Frey KA, Navarro SM, Kotelchuck M, Lu MC. The clinical content of preconception care: preconception care for 
men. Am J Obstet Gynecol. 2008;199(6):S389-S395. doi:10.1016/j.ajog.2008.10.024.

21. Kim H, Kim SK, Yu EJ, et al. The prevalence of positive urinary cotinine tests in Korean infertile couples and the effect of smoking on assisted conception outcomes. Clin Exp Reprod Med. 2015;42(4):136-42. doi:10.5653/ cerm.2015.42.4.136

22. AndersonK,Norman RJ,Middleton P.Preconceptionlifestyle advice for people with subfertility. Cochrane Database Syst Rev 2010;(4):CD008189. doi:10.1002/14651858.CD008189. pub2.

23. Waylen AL, Metwally M, Jones GL, Wilkinson AJ, Ledger WL. Effects of cigarette smoking upon clinical outcomes of assisted reproduction: a meta-analysis. Hum Reprod Update. 2009;15(1):31-44. doi:10.1093/humupd/dmn046.

24. Cozzolino DJ, Lamb DJ. Are endocrine disruptors a cause of male reproductive defects? Contemporary Urology. 2000;19:69-74.

25. Thompson ST. Prevention of male infertility: an update. Urol Clin North Am. 1994;21(3):365-76.

26. Buffum J. Pharmacosexology update: prescription drugs and sexual function. J Psychoactive Drugs. 1986;18(2):97106. doi:10.1080/02791072.1986.10471390.

27. Nudell DM, Monoski MM, Lipshultz LI. Common medications and drugs: how they affect male fertility. Urol Clin North Am. 2002;29(4):965-73.

28. Hershlag A, Cooper GW, Benoff S. Pregnancy following discontinuation of a calcium channel blocker in the male partner. Hum Reprod. 1995;10(3):599-606.

29. Debruyne FM. Alpha blockers: are all created equal? Urology 2000;56(5 Suppl 1):20-2.

30. Schlegel PN, Chang TS, Marshall FF. Antibiotics: potential hazards to male fertility. Fertil Steril. 1991;55(2):235-42.

31. Hjollund NH, Jensen TK, Bonde JP, Henriksen TB, Andersson AM, Kolstad HA, et al. Distress and reduced fertility: a follow-up study of first-pregnancy planners. Fertil Steril 1999;72(1):47-53.

32. Boivin J, Griffiths E, Venetis CA. Emotional distress in infertile women and failure of assisted reproductive technologies: meta-analysis of prospective psychosocial studies. BMJ 2011;342:d223. doi:10.1136/bmj.d223.

33. Frederiksen Y, Farver-Vestergaard I, Skovgård NG, Ingerslev HJ, Zachariae R. Efficacy of psychosocial interventions for psychological and pregnancy outcomes in infertile women and men: a systematic review and meta-analysis. BMJ Open 2015;5(1):e006592. doi:10.1136/bmjopen-2014-006592.

34. Hammarberg K, Astbury J, Baker H. Women's experience of IVF: a follow-up study. Hum Reprod. 2001;16(2):374-83.

35. Domar AD. Impact of psychological factors on dropout rates in insured infertility patients. Fertil Steril. 2004;81(2):2713. doi:10.1016/j.fertnstert.2003.08.013.

36. Olivius C, Friden B, Borg G, Bergh C. Why do couples discontinue in vitro fertilization treatment? A cohort study. Fertil Steril. 2004;81(2):258-61. doi:10.1016/j. fertnstert.2003.06.029.

37. Khademi A, Alleyassin A, Amini M, Ghaemi M. Evaluation of sexual dysfunction prevalence in infertile couples. J Sex Med. 2008;5(6):1402-10. doi:10.1111/j.17436109.2007.00687.x.

38. Wischmann TH. Sexual disorders in infertile couples. J Sex Med. 2010;7(5):186876. doi:10.1111/j.17436109.2010.01717.x.

39. Tao P, Coates R, Maycock B. The impact of infertility on sexuality: a literature review. Australas Med J. 2011;4(11):620-7. doi:10.4066/AMJ.20111055.

40. Ainsworth BE, Haskell WL, Whitt MC, et al. Compendium of physical activities: an update of activity codes and MET intensities. Med Sci Sports Exerc. 2000;32(9 Suppl):S498-S504.

41. Haskell WL, Lee IM, Pate RR, et al. Physical activity and public health: updated recommendation for adults from the American College of Sports Medicine and the American Heart Association. Circulation. 2007;116(9):1081-93. doi:10.1161/CIRCULATIONAHA.107.185649.

42. Mutsaerts MA, Groen H, Huiting HG, et al. The influence of maternal and paternal factors on time to pregnancy-a dutch population-based birth-cohort study: the GECKO drenthe study. Hum Reprod. 2012;27(2):583-93. doi:10.1093/ humrep/der429.

43. Brannian JD. Obesity and fertility. S D Med. 2011;64(7):2514.

44. Vaamonde D, Da Silva-Grigoletto ME, Garcia-Manso JM, Vaamonde-Lemos R, Swanson RJ, Oehninger SC. Response of semen parameters to three training modalities. Fertil Steril. 2009;92(6):1941-6. doi:10.1016/j. fertnstert.2008.09.010.

45. Rooney KL, Domar AD. The impact of lifestyle behaviors on infertility treatment outcome. Curr Opin Obstet Gynecol. 2014;26(3):181-5. doi:10.1097/GCO.0000000000000069.

46. Redman LM. Physical activity and its effects on reproduction. Reprod Biomed Online. 2006;12(5):579-86.

47. Wise LA, Rothman KJ, Mikkelsen EM, Sørensen HT, Riis $\mathrm{AH}$, Hatch EE. A prospective cohort study of physical activity and time to pregnancy. Fertil Steril. 2012;97(5):113642. doi:10.1016/j.fertnstert.2012.02.025.

48. What's In a Cigarette? American Lung Association website. http://www.lung.org/stop-smoking/about-smoking/factsfigures/whats-in-a-cigarette.html.

49. Practice Committee of American Society for Reproductive Medicine. Smoking and infertility. Fertil Steril. 2008;90(5 Suppl):S254-S259. doi:10.1016/j.fertnstert.2008.08.035.

50. Windham GC, Mitchell P, Anderson M, Lasley BL. Cigarette smoking and effects on hormone function in premenopausal women. Environ Health Perspect. 2005;113(10):1285-90.

51. Künzle $\mathrm{R}$, Mueller $\mathrm{MD}$, Hänggi $\mathrm{W}$, Birkhäuser $\mathrm{MH}$, Drescher H, Bersinger NA. Semen quality of male smokers and nonsmokers in infertile couples. Fertil Steril. 2003;79(2):287-91.

52. Calogero A, Polosa R, Perdichizzi A, et al. Cigarette smoke extract immobilizes human spermatozoa and induces sperm apoptosis. Reprod Biomed Online. 2009;19(4):56471.

53. Soares SR, Melo MA. Cigarette smoking and reproductive function. Curr Opin Obstet Gynecol. 2008;20:281-91. doi:10.1097/GCO.0b013e3282fc9c1e

54. Hamadneh SH, Kassab, M. Hamadneh, J. Amarin, Z. Sudden unexpected infant death in Jordan and child caring environments. Pediatr Int. 2016;58(12):1333-6. doi:10.1111/ped.13016.

55. Muthusami KR, Chinnaswamy P. Effect of chronic alcoholism on male fertility hormones and semen quality. Fertil Steril. 2005;84(4):919-24. doi:10.1016/j. fertnstert.2005.04.025.

56. Gaur DS, Talekar MS, Pathak VP. Alcohol intake and cigarette smoking: impact of two major lifestyle factors on male fertility. Indian J Pathol Microbiol. 2010;53(1):35-40. 
doi:10.4103/0377-4929.59180.

57. Eggert J, Theobald H, Engfeldt P. Effects of alcohol consumption on female fertility during an 18-year period. Fertil Steril. 2004;81(2):379-83. doi:10.1016/j. fertnstert.2003.06.018.

58. Revonta M, Raitanen J, Sihvo S, et al. Health and life style among infertile men and women. Sex Reprod Healthc. 2010;1(3):91-8. doi:10.1016/j.srhc.2010.06.002.

59. Rasch V. Cigarette, alcohol, and caffeine consumption: Risk factors for spontaneous abortion. Acta Obstet Gynecol Scand. 2003;82(2):182-8.

60. Gormack AA, Peek JC, Derraik JG, Gluckman PD, Young NL, Cutfield WS. Many women undergoing fertility treatment make poor lifestyle choices that may affect treatment outcome. Hum Reprod. 2015;30(7):1617-24. doi:10.1093/humrep/dev094.

61. Gollenberg AL, Liu F, Brazil C, et al. Semen quality in fertile men in relation to psychosocial stress. Fertil Steril. 2010;93(4):1104-11. doi:10.1016/j.fertnstert.2008.12.018.

62. Macdonald AA, Stewart AW, Farquhar CM. Body mass index in relation to semen quality and reproductive hormones in New Zealand men: a cross-sectional study in fertility clinics. Hum Reprod. 2013;28(12):3178-87. doi:10.1093/humrep/det379.

63. Pook M, Tuschen-Caffier B, Kubek J, Schill WB, Krause W. Personality, coping and sperm count. Andrologia. 2005;37(1):29-35. doi:10.1111/j.1439-0272.2004.00647.x.
64. Zorn B, Auger J, Velikonja V, Kolbezen M, Meden-Vrtovec $\mathrm{H}$. Psychological factors in male partners of infertile couples: Relationship with semen quality and early miscarriage. Int J Androl. 2008;31(6):557-64. doi:10.1111/ j.1365-2605.2007.00806.x.

65. Frederiksen Y, Farver-Vestergaard I, Skovgård NG, Ingerslev HJ, Zachariae R. Efficacy of psychosocial interventions for psychological and pregnancy outcomes in infertile women and men: a systematic review and meta-analysis. BMJ Open. 2015;28:5(1):e006592. doi:10.1136/bmjopen-2014-006592.

66. Louis GM, Lum KJ, Sundaram R, et al. Stress reduces conception probabilities across the fertile window: evidence in support of relaxation. Fertil Steril. 2011;95(7):2184-9. doi:10.1016/j.fertnstert.2010.06.078.

67. Anderson K, Niesenblat V, Norman R. Lifestyle factors in people seeking infertility treatment - A review. Aust N Z J Obstet Gynaecol. 2010;50(1):8-20. doi:10.1111/j.1479828X.2009.01119.x.

68. Klonoff-Cohen H, Chu E, Natarajan L, Sieber W. A prospective study of stress among women undergoing in vitro fertilization or gamete intrafallopian transfer. Fertil Steril. 2001;76(4):675-87.

69. Schilling K, Toth B, Rösner S, Strowitzki T, Wischmann T. Prevalence of behaviour-related fertility disorders in a clinical sample: results of a pilot study. Arch Gynecol Obstet. 2012; 286(5):1307-14. doi:10.1007/s00404-0122436-x.

Copyright ( 2017 The Author (s); This is an open-access article distributed under the terms of the Creative Commons Attribution License (http://creativecommons.org/licenses/by/4.0), which permits unrestricted use, distribution, and reproduction in any medium, provided the original work is properly cited. 